\title{
Nutrients Dynamics in the Surface Waters of the Black Sea
}

\author{
N. A. Orekhova \\ Marine Hydrophysical Institute of RAS, Sevastopol, Russian Federation \\ natalia.orekhova@mhi-ras.ru
}

Purpose. One of the key characteristics of water quality and marine ecosystems' sustainability is nutrients supply, which are the main factors of phytoplankton bloom. Since the mid-20 ${ }^{\text {th }}$ century, in the northwestern Black Sea and on its western shelf significant changes in nutrients concentrations took place, which were manifested in increase of the inorganic nitrogen and phosphorus concentrations and decrease of the dissolved silicon content, that in its turn, led to a strong anthropogenic eutrophication of the above-mentioned regions. The aim of the work is to assess the current state of the Black Sea based on the data on the nutrients distribution and dynamics in the surface water layer.

Methods and Results. The data obtained in the cruises of R/V Professor Vodyanitsky in 2016-2019 were analyzed. The main regions under study included the deep part of the Black Sea, as well as the Crimean and Caucasian sectors of the economic zone of Russia. The data obtained showed significant variability in the nutrients concentration both in the coastal and open areas.

Conclusions. A decrease of nutrients concentration in 2016-2019 as compared to that in 2009-2014 was noted, that can indicate a decrease in the eutrophication degree and an improvement of the Black Sea waters quality. Intra-annual variability of the nutrients concentration in the sea surface layer is observed. No pronounced features in spatial variability of the nutrients concentration in this layer were revealed. It is assumed that in the central deep part of the sea, their concentrations are governed mainly by the physical processes of water transfer. In addition to physical transport, the increased nutrients concentrations in the coastal areas are, probably, also related to influence of the anthropogenic factor, namely inflow of nutrients from the coastal sources or their formation resulting from the biogeochemical processes with organic matter.

Keywords: Black Sea, hydrochemical characteristics, nutrients

Acknowledgments: the work was carried out within the framework of the state task No. 0555-20210004, and the RFBR projects No. 18-05-80028 "Studies and scaling of water dynamics and biogeochemical processes in development of oxygen deficit and sulfidic conditions in coastal areas of the Crimea and the Kerch Strait" (analysis of the data obtained in the coastal regions of the Black Sea) and No. 21-55-52001 "Comparing structure, functions and niche differentiation in marine picophytoplankton communities with and without Prochlorococcus cyanobacteria in the East China Sea and the Black Sea”.

For citation: Orekhova, N.A., 2021. Nutrients Dynamics in the Surface Waters of the Black Sea. Physical Oceanography, [e-journal] 28(6), pp. 660-676. doi:10.22449/1573-160X-2021-6-660-676

DOI: doi:10.22449/1573-160X-2021-6-660-676

(C) N. A. Orekhova, 2021

(C) Physical Oceanography, 2021

\section{Introduction}

The Black Sea is one of the world's largest inland semi-enclosed seas [1] with limited water exchange and pronounced vertical density stratification. In view of the geographical location and structural features of the water column (the presence of a hydrogen sulfide layer below 120-150 m), the Black Sea is the subject of increased attention and active research [1-11]. In addition, the activities of the countries situated on its shores (Russia, Ukraine, Romania, Bulgaria, Turkey, Georgia) affect the characteristics of the sea ecosystem both directly and through 660 
river runoff, the total contribution of which averages $350 \mathrm{~km}^{3} /$ year [1]. The northwestern part of the Black Sea is most affected by river runoff ( $>70 \%$ of river runoff). The southeastern part of the sea with the rivers of the Caucasus receives $13 \%$ of the runoff, the contribution of the Turkish coast rivers is estimated at about $10 \%[1,11]$. River runoff is a powerful source of fresh water, as well as suspended matter, nutrients, organic matter and pollutants. Thus, the influx of river runoff, as well as an active anthropogenic load both in the coastal areas of the sea and in its central part (due to active navigation) can lead to various changes in the marine ecosystem, some of which may be critical. In addition to the anthropogenic impact, the Black Sea is sensitive to climate change [11-13]. The paper [14] discusses the effect of global warming on the change in the physical characteristics of the Black Sea water column since 1993: an increase in the average annual temperature of the surface water layer (on average by $0.25^{\circ} \mathrm{C}$ ), an increase in the sea level and river runoff are noted.

One of the key characteristics of water quality and stability of marine systems in general, and for the Black Sea in particular, is the supply of nutrients, which are the main factors of phytoplankton bloom (the basis of a food base for fish and mollusks) and changes in its biomass $[15,16]$. An excess of nutrients can have a devastating effect on the marine system, leading to eutrophication, hypoxia and anoxia, outbreaks of algal blooms, the death of algae and coral, as well as to a decrease in fish and shellfish populations. So, for example, in the Black Sea from the mid-1980s to the mid-1990s a large biomass of phytoplankton was observed, which, according to some researchers, was a consequence of anthropogenic pollution $[11,17]$.

The main nutrients that determine the functioning of marine ecosystems include dissolved forms of nitrogen, phosphorus and silicon. Phosphorus and nitrogen are present in the seawater in the form of a variety of inorganic and organic compounds, while silicon is found mainly in the form of inorganic compounds. Inorganic nitrogen compounds include ammonium $\left(\mathrm{NH}_{4}{ }^{+}\right)$, nitrite $\left(\mathrm{NO}_{2}{ }^{-}\right)$and nitrate $\left(\mathrm{NO}_{3}{ }^{-}\right)$ions, which are interconnected, can pass into each other and therefore are considered together. The most widespread and most studied form of inorganic phosphorus are phosphates $\left(\mathrm{PO}_{4}{ }^{3-}\right)$, silicon - silicic acid $\left(\mathrm{SiO}_{2} \cdot n \mathrm{H}_{2} \mathrm{O}\right)$.

It was determined $[11,16,17]$ that from the mid- $20^{\text {th }}$ century in the northwestern part of the sea and on the western shelf significant changes occurred in the nutrient's concentration, which manifested themselves in an increase in the concentration of inorganic nitrogen and phosphorus and in a decrease in the dissolved silicon content. These changes took place most dramatically in the 1970s and 1980s, which led to a powerful anthropogenic eutrophication of the abovementioned regions. With some time delay, the accumulation of dissolved nitrogen was also observed in the deep-water basin. It was the most pronounced in the period from the mid-1970s to the mid-1990s. In addition, over the past 40 years in the Black Sea due to changes in the concentration, composition and ratio of nutrients in the pycnocline and the cold 
intermediate layer, there has been a sharp increase in the amount of coccolithophorids and a decrease in the biomass of silicoflagellates [11].

The purpose of this work is to assess the current state of the Black Sea based on data on the distribution and dynamics of nutrients in the surface water layer.

\section{Methods and materials}

The paper analyzes field data obtained in 2016-2019 during expeditionary research on R/V Professor Vodyanitsky. The surveys were carried out in different hydrological seasons - spring (April - June), summer (July - September), autumn (October - December) [10]: 30.06.2016 - 20.07.2016, cruise 87; 30.09.201619.10.2016, cruise 89; 16.11.2016-05.12.2016, cruise 91; 22.04.2017 05.05.2017, cruise 94; 14.06.2017-03.07.2017, cruise 95; 14.11.2017 28.11.2017, cruise 98; 14.12.2017-28.12.2017, cruise 101; 09.06.201802.07.2018, cruise 102; 28.08.2018-20.09.2018, cruise 103; 18.11.201810.12.2018, cruise 105; 11.07.2019 - 05.08.2019, cruise 108. The main research areas were the deep-water part of the Black Sea, as well as the Crimean and Caucasian sectors of the economic zone of Russia. The scheme of the study area and sampling points is shown in Fig. 1.

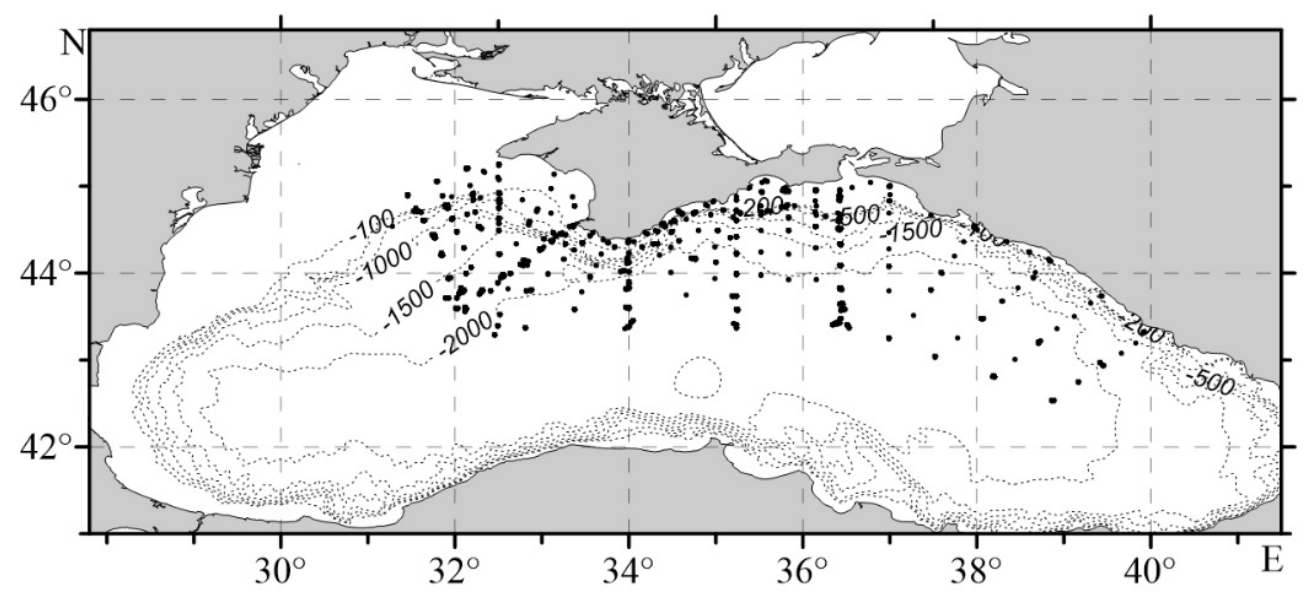

F i g. 1. Region under study and sampling points in 2016-2019

In order to study the features of nutrient concentration spatial variability, the study area was conditionally divided into coastal (limited by the 100-m isobath) and open (> $100 \mathrm{~m}$ ) parts. The paper considers data for the surface water layer.

Seawater sampling, temperature and salinity measurements at hydrochemical stations were carried out using the SeaBird 911 plus measuring complex. Chemical analysis of the samples included the determination of concentrations of the silicic acid, and inorganic forms of nitrogen. Ammonium concentration was determined directly on board the vessel. Samples filtered through a membrane filter with a pore size of $0.45 \mu \mathrm{m}$ were subsequently frozen and delivered to the laboratory to 
determine the concentrations of the sum of nitrates - nitrites, phosphates, and silicic acid.

Mineral forms of nutrients were analyzed photometrically. When determining the concentration of silicic acid, a correction for salinity [18] was made. Ammonium was determined using a modified Sagi - Solorzano method for the seawater, based on the determination of an indophenolic dye formed in an alkaline medium from phenol, ammonia, and hypochlorite. The method uses nitroprusside as a reaction catalyst, that significantly increases its sensitivity [19], which is $0.05 \mu \mathrm{M} *$. In order to determine the sum of nitrates and nitrites on a flow-through autoanalyzer, we used the method of reducing nitrates to nitrites using copper-bonded cadmium. With a minimum detectable nitrate concentration of $0.36 \mu \mathrm{M}$, the method error is $\pm 0.20 \mu \mathrm{M} * *$. The error in the determination of inorganic phosphorus by the method based on the formation of a blue phosphoromolybdenum complex is $\pm 2-15 \%$ (the maximum error is observed at up to $0.20 \mu \mathrm{M}$ concentrations) $* *$. Determination of the silicic acid concentration is based on the formation of a blue silicomolybdenum complex. The method error ranges from 3 to $20 \%$, with the maximum determination error corresponding to concentrations not exceeding $0.36 \mu \mathrm{M} * *$.

\section{Results}

According to the data acquired in 2016-2019, a significant variability in the concentration of nutrients both in the coastal and in the open regions of the Black Sea (Fig. 2) can be traced back. At the same time, the difference between coastal and open areas was either minimal or not observed (Table).

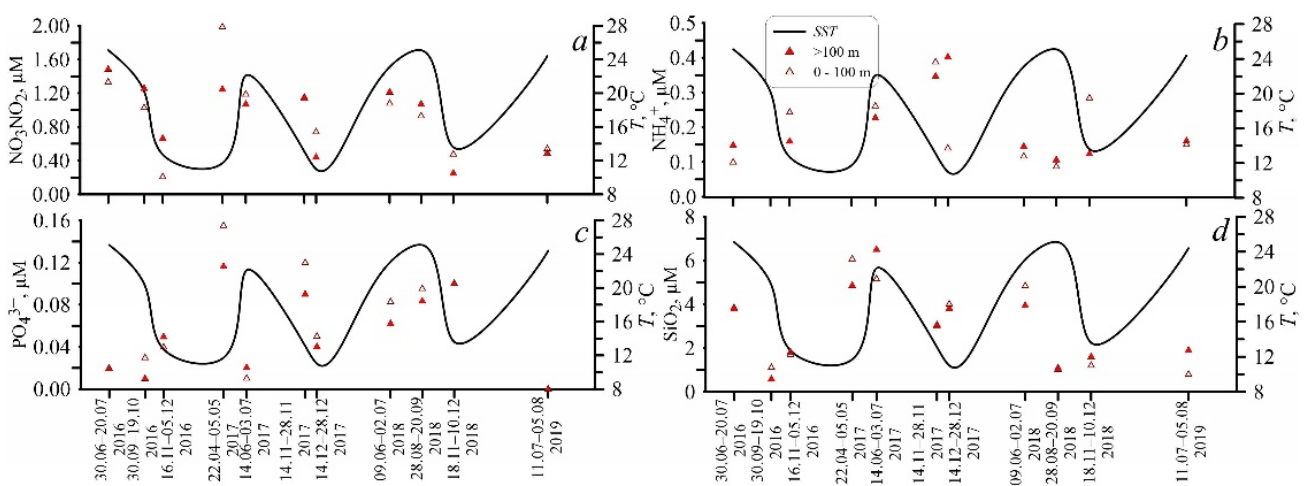

F i g. 2. Dynamics of the nutrients concentration in the northern part of the Black Sea based on the data for 2016-2019 (solid line is the sea surface temperature)

* Sapozhnikov, V.V., ed., 2003. [Guidelines for the Chemical Analysis of Marine and Fresh Waters in Environmental Monitoring of Fishery Water Bodies and Potential Fishery Areas of the World Ocean]. Moscow: VNIRO Publishing House, 202 p. (in Russian).

** Guiding document 52.10.243-293. [Guidelines for the Chemical Analysis of Marine Waters]. Saint Pitersburg: Gidrometeoizdat, 1993. 264 p. (in Russian). 
Average temperature of the surface water layer, the nutrients concentration (median) $(\mu \mathrm{M})$ and the range of their variation for the coastal regions $(\leq 100 \mathrm{~m})$ and the open part (> $100 \mathrm{~m})$ of the Black Sea

\begin{tabular}{l|c|c|c|c|c|c|c|c|c}
\hline Cruise & $T,{ }^{\circ} \mathrm{C}$ & \multicolumn{2}{|c|}{$\Sigma \mathrm{NO}_{2} \mathrm{NO}_{3}$} & \multicolumn{2}{|c|}{$\mathrm{NH}_{4}$} & \multicolumn{2}{c|}{$\mathrm{PO}_{4}$} & \multicolumn{2}{c}{$\mathrm{SiO}_{2}$} \\
\cline { 3 - 9 } & & $\leq 100 \mathrm{~m}$ & $>100 \mathrm{~m}$ & $\leq 100 \mathrm{~m}$ & $>100 \mathrm{~m}$ & $\leq 100 \mathrm{~m}$ & $>100 \mathrm{~m}$ & $\leq 100 \mathrm{~m}$ & $>100 \mathrm{~m}$ \\
\hline & & & & & & & & \\
\hline
\end{tabular}

PV $87 \quad 25.1$

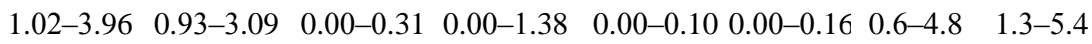
1.03
1.26
$0.03 \quad 0.01$
$1.1 \quad 0.6$

PV $89 \quad 20.2$

$0.62-2.08 \quad 0.70-7.07$

$0.00-0.07 \quad 0.00-0.20 \quad 0.3-1.9 \quad 0.3-1.8$

$\begin{array}{llllllll}0.21 & 0.66 & 0.24 & 0.16 & 0.04 & 0.05 & 1.7 & 1.8\end{array}$

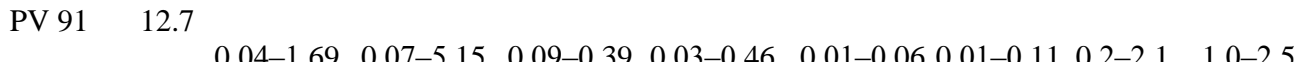
1.99
1.25
0.16
0.12
6.1
4.9

PV $94 \quad 11.7$

$0.87-2.55 \quad 0.27-5.48$

$0.02-0.94 \quad 0.02-0.19 \quad 1.5-9.4 \quad 1.4-7.3$
1.19
1.07
0.26
0.23
0.01
0.02
5.2
6.5

PV $95 \quad 22.1$

$\begin{array}{lllllll}0.63-2.51 & 0.11-3.42 & 0.15-0.36 & 0.13-0.39 & 0.00-0.03 & 0.00-0.18 & 4.4-78\end{array}$

$4.1-8.3$
1.15
1.14
$0.39 \quad 0.35$
$0.12 \quad 0.09$
$3.1 \quad 3.0$

PV $98 \quad 13.1$

$\begin{array}{llllllll}0.96-1.63 & 0.49-3.88 & 0.00-3.23 & 0.00-1.54 & 0.01-0.24 & 0.00-0.21 & 2.3-3.7 & 1.9-3.9\end{array}$

PV $101 \quad 11.0$
0.74
0.44
0.14
0.40
0.05
0.04
$4.0 \quad 3.8$

$\begin{array}{llllllll}0.48-0.99 & 0.02-3.27 & 0.06-0.21 & 0.05-1.15 & 0.01-0.09 & 0.00-0.26 & 3.2-4.9 & 2.2-5.3\end{array}$
1.08
1.21
0.12
0.14
0.08
0.06
4.8
3.9

PV $102 \quad 23.1$

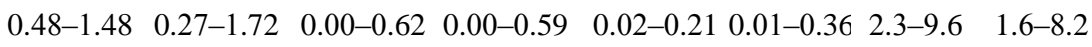
0.93
1.07
0.09
0.11
0.10
0.08
$1.1 \quad 1.0$

PV $103 \quad 25.1$

$\begin{array}{llllllll}0.00-1.74 & 0.00-1.67 & 0.00-0.73 & 0.00-0.53 & 0.00-0.51 & 0.00-1.03 & 0.0-3.6 & 0.0-5.8\end{array}$
0.48
0.25
0.28
0.12
0.10
0.10
1.2
1.6

PV 10513.6

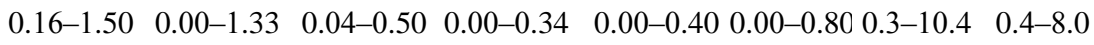
0.54
0.49
0.15
0.16
0.00
0.00
$\begin{array}{ll}0.8 & 1.9\end{array}$

PV $108 \quad 24.4$

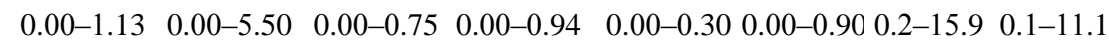

N o t e : PV is R/V Professor Vodyanitsky; “-” is not determined. 
In spring (cruises 94, 95, 102), when the intensity of vertical convection is weaker than in winter, the main source of nutrients is the river runoff. High concentrations of oxidized forms of nutrients observed during this period (Fig. 2, Table), among other factors, create favorable conditions for the activation of phytoplankton bloom processes. By the end of spring, the concentration of nutrients decreases due to their utilization by phytoplankton, while increased concentrations of ammonium $(0.23 \pm 0.06 \mu \mathrm{M})$ are noted, their share was $20 \%$. An increase in the concentration of silicic acid from April to June (Fig. 2) is probably associated with its accumulation as a result of its inflow with deep waters and river runoff (which reaches its maximum distribution over the sea area after a spring flood [1]), and as a result of dissolution suspended matter of terrigenous and biogenic origin, while nitrogen and phosphorus are consumed during biological and chemical processes.
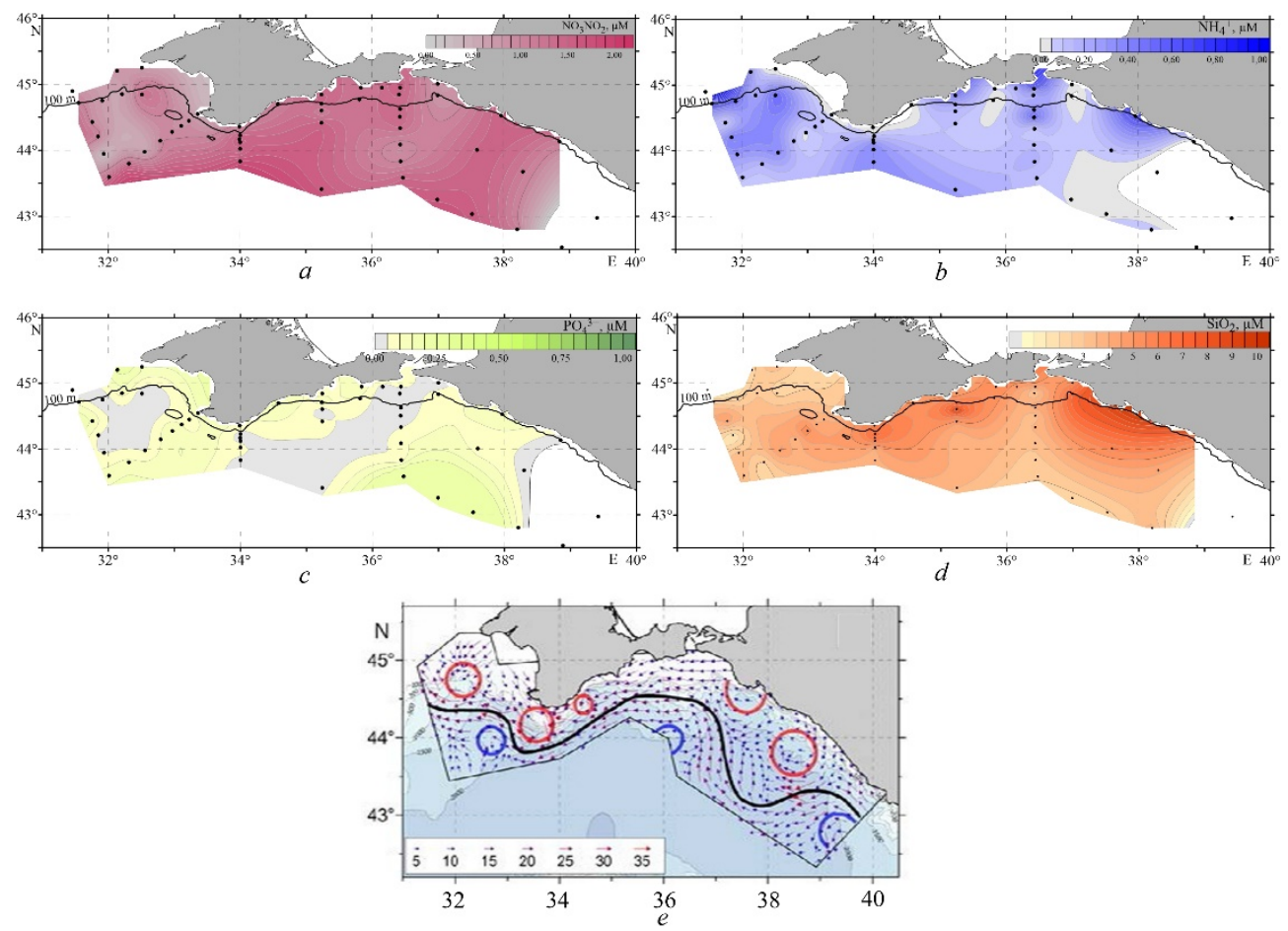

F i g. 3. Spatial variability of the nutrients concentration $(a-d)$ and vectors of the instrumentally measured currents at the $10 \mathrm{~m}$ depth $(e,[20])$ based on the data of the $102^{\text {nd }}$ cruise of R/V Professor Vodyanitsky

It should be noted that there were no pronounced features in the spatial variability of the concentration of nutrients (Fig. 3, $a-d$ ). In the middle of spring, the predominance of the concentration of all nutrients in the coastal part was noted (Fig. 2, Table), which may be due to the contribution of river runoff. In late spring, 
the difference in the concentration of nutrients in the coastal part and in the open areas was not observed (Fig. 2, Table), however, a spatial heterogeneity of their distribution was noted (Fig. 3, $a-d$ ). It coincides with the dynamics of waters (Fig. 3, e): the transport of nutrients occurs due to the Sea of Azov waters along the eastern coast of Crimea, river runoff in the northwestern part and in the region of the Caucasian coast [20].

In addition, increased concentrations of inorganic forms of nitrogen and phosphorus were found in the coastal part (Fig. 3, $a-d$ ), in areas with significant anthropogenic load (the area of the Kerch Strait, Feodosiya Bay [21], Karkinitsky Bay [22]). Also, local maxima of the concentration of ammonium $(0.62 \mu \mathrm{M})$ and silicic acid $(9.55 \mu \mathrm{M})$ were noted on the coast of Krasnodar Territory in the area of the Afips River runoff (Fig. 3, $b, d$ ). This river is distinguished by high mineralization [23], the maximum value of its runoff occurs in spring (up to $272 \mathrm{~m}^{3} / \mathrm{s}$ ) [24]. With the distance from the coast, the concentration of ammonium decreases down to $0.10 \mu \mathrm{M}$ (Fig. 3, b), silicic acid - to $5.58 \mu \mathrm{M}$ (Fig. 3, $d$ ).

In summer (cruises $87,103,108$ ) a decrease in the concentration of nutrients was noted in comparison with spring (Fig. 2, Table). This is primarily due to their involvement in biological and chemical processes and their consumption as a result of photosynthesis $[7,16]$ with the absence of convective transport of deep waters and weakening of the transport by the Rim Current, coastal currents and gyres [1]. During this period, the contribution of anthropogenic sources (mainly municipal wastewater) increases in coastal areas. However, there was no pronounced difference in the concentration of nutrients in coastal and deep-sea areas (Table).

The content of inorganic forms of nitrogen in comparison with the spring period decreased to $\sim 1.00 \mu \mathrm{M}$ for the sum of nitrates - nitrites (with a maximum concentration of $3.96 \mu \mathrm{M}$ ) and to $\sim 0.13 \mu \mathrm{M}$ for ammonium (maximum $1.38 \mu \mathrm{M}$ ). The proportion of nitrogen reduced forms was $17 \%$, which may indicate the absence of a significant contribution from the remineralization of organic matter. The concentration of silicic acid by the summer period decreased almost two times, to $2.15 \mu \mathrm{M}$ (maximum $15.90 \mu \mathrm{M}$ ). The phosphate content was below the detection limit $(0.02 \mu \mathrm{M})$. Moreover, in 2016-2019 a decrease in the average concentration of the sum of nitrates - nitrites from 1.46 to $0.50 \mu \mathrm{M}$, silicic acid from 3.75 to $1.65 \mu \mathrm{M}$ and an increase in the average concentration of ammonium from 0.11 to $0.16 \mu \mathrm{M}$. The contribution of ammonium to total nitrogen increased from $19 \%$ (2016) to $24 \%$ (2019).

In July, the spatial distribution of nutrients differed from survey to survey by its heterogeneity, which may be due to the significant variability of water dynamics [20] and the heterogeneity of biological and chemical processes. However, in September 2018, the distribution of nutrients was homogeneous both in the open part and in the coastal areas of the studied area (Fig. 4, $a-d$ ). Their maximum concentrations were typical for the Caucasian sector, with the exception of silicic acid. An insignificant concentration of silicic acid (Fig. 2, Table) is the main 666 
feature of this period. Nevertheless, its highest concentrations were noted in the eastern part of Crimea, slightly southward of Feodosiya Bay (Fig. 4, d), where, according to [20, 25], anticyclonic gyres are formed (Fig. 4, e).
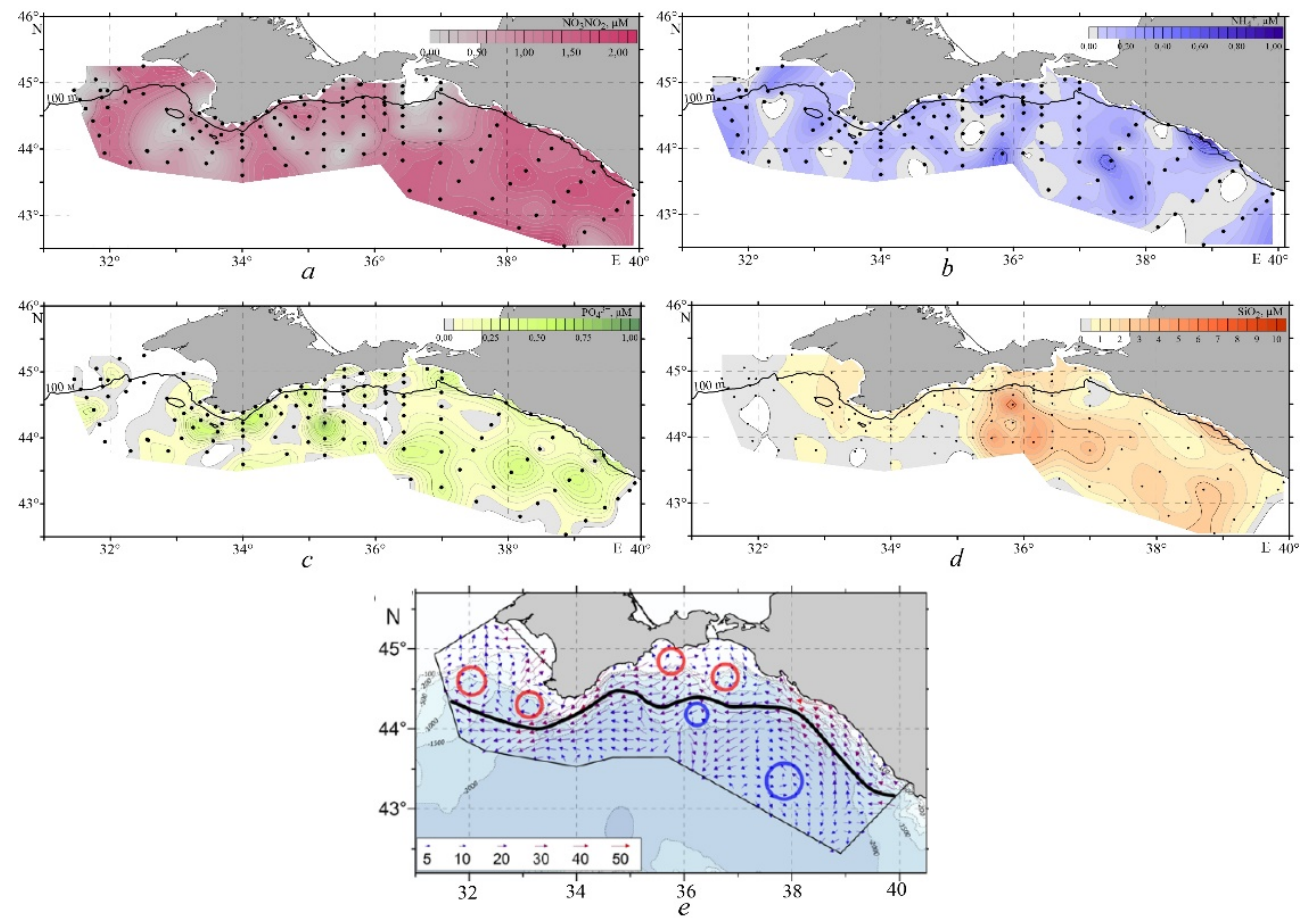

F i g. 4. Spatial variability of the nutrients concentration $(a-d)$ and vectors of the instrumentally measured currents at the $25 \mathrm{~m}$ depth (e, [20]) based on the data of the $103^{\text {rd }}$ cruise of R/V Professor Vodyanitsky

In autumn (cruises 89, 91, 98, 101, 105), in general, a decrease in the concentration of nutrients to $\sim 0.73 \mu \mathrm{M}$ takes place (Fig. 2, Table). However, during the period, a change in their content is observed. At the end of October increased wind activity and the destruction of the upper quasi-homogeneous layer (UML) [1] contribute to the nutrient flow with deep waters into the surface layer. This, in turn, creates the prerequisites for an autumn wave of phytoplankton bloom in the first half of November [26]. With the attenuation of the activity of chemical and biological processes (by the end of November, in December), there is a decrease in the concentration of oxidized forms of nutrients and an increase in the contribution of reduced forms (ammonium) due to remineralization of organic matter.

No pronounced differences in the concentration of nutrients in the coastal and open parts of the area under study were observed (Fig. 2, 5, Table). In 2018, the maximum concentrations of oxidized forms of nitrogen and phosphates were 
noted in the western part of the studied area (Fig. 5, $a, c$ ), while the distribution of ammonium was inverse - its maximum concentrations were noted along the coast of the Caucasian coast and in the eastern part Crimean coast (Fig. 5, b). Local maxima of silicic acid concentration were observed on the Caucasian coast and in the Feodosiya Bay area (Fig. 5, $d$ ).

During the period under consideration, there is an interannual variability in the concentration of nutrients (Fig. 2), which may indicate a different intensity of biological and chemical processes and water dynamics. The same applies to the features of spatial distribution. From cruise to cruise, the areas with pronounced extremes of nutrient concentrations also changed.
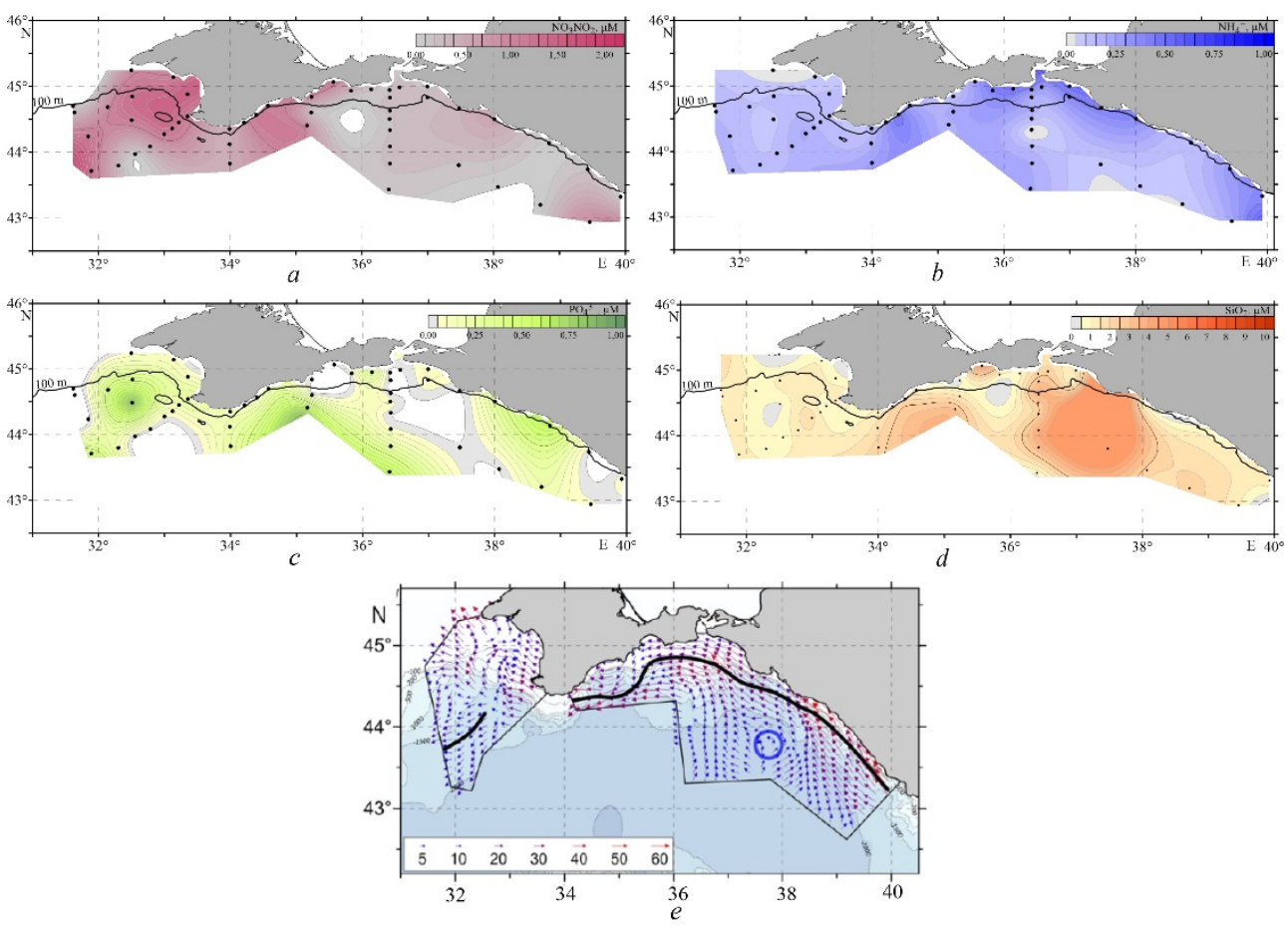

F i g. 5. Spatial variability of the nutrients concentration $(a-d)$ and vectors of the instrumentally measured currents at the $10 \mathrm{~m}$ depth $(e,[20])$ based on the data of the $105^{\text {th }}$ cruise of R/V Professor Vodyanitsky

\section{Discussion of the results}

The distribution of nutrients shows a pronounced intra-annual dynamics (Fig. 6).

According to the literature [16], the maximum concentrations of nutrients occur in winter (January - March), which is due to their entry into the upper layer due to the processes of vertical convection and insignificant consumption by phytoplankton. 
In spring, river runoff serves as an additional source of nutrients $[1,11]$. However, in general, by April the content of inorganic nitrogen decreases due to a decrease in the flux of its oxidized forms from deep layers [16]. In this case, the proportion of reduced forms of nitrogen increases (up to 85\%) due to an increase in the reduced flow. The phosphorus content in winter and spring reaches 0.1-0.2 $\mu \mathrm{M}$ [16]. According to our data, in April the maximum concentrations of phosphates $(0.15 \mu \mathrm{M})$, the sum of nitrates - nitrites $(1.45 \mu \mathrm{M})$ and silicic acid $(5.81 \mu \mathrm{M})$ takes place (Fig. 6, Table). By May, the organic carbon of the UML is consumed and the concentration of nutrients decreases, while inorganic nitrogen is consumed first of all. In the same period, active blooming of phytoplankton begins [16], a deficiency of nitrates in relation to phosphates is noted (Fig. 6). In June, which is the peak of coccolithophorids bloom [27], the content of nitrogen inorganic forms is $1.2-1.3 \mu \mathrm{M}$, and the proportion of reduced forms of nitrogen is $20 \%$. A decrease in the

concentration of phosphates by 2-3 times is observed, as a result of which they can become a limiting factor of photosynthesis. The silicic acid content remains high (4-6 $\mu \mathrm{M})$. This can be explained by the fact that as a result of bloom, nitrogen and phosphorus are consumed first, and after their depletion - silicon, which is also confirmed by the data on the phytoplankton species composition: the predominance of coccolithophorids in June and diatoms in July [16, 27, 28]. By July, the content of phosphates is below the detection limit $(<0.02 \mu \mathrm{M})$, and the content of nitrogen and silicic acid also decreases. Due to the deficiency of nutrients, in particular phosphorus, it should be expected that photosynthesis is attenuated. The minimum concentrations of silicates are observed in September - October $(\sim 1 \mu \mathrm{M})$.
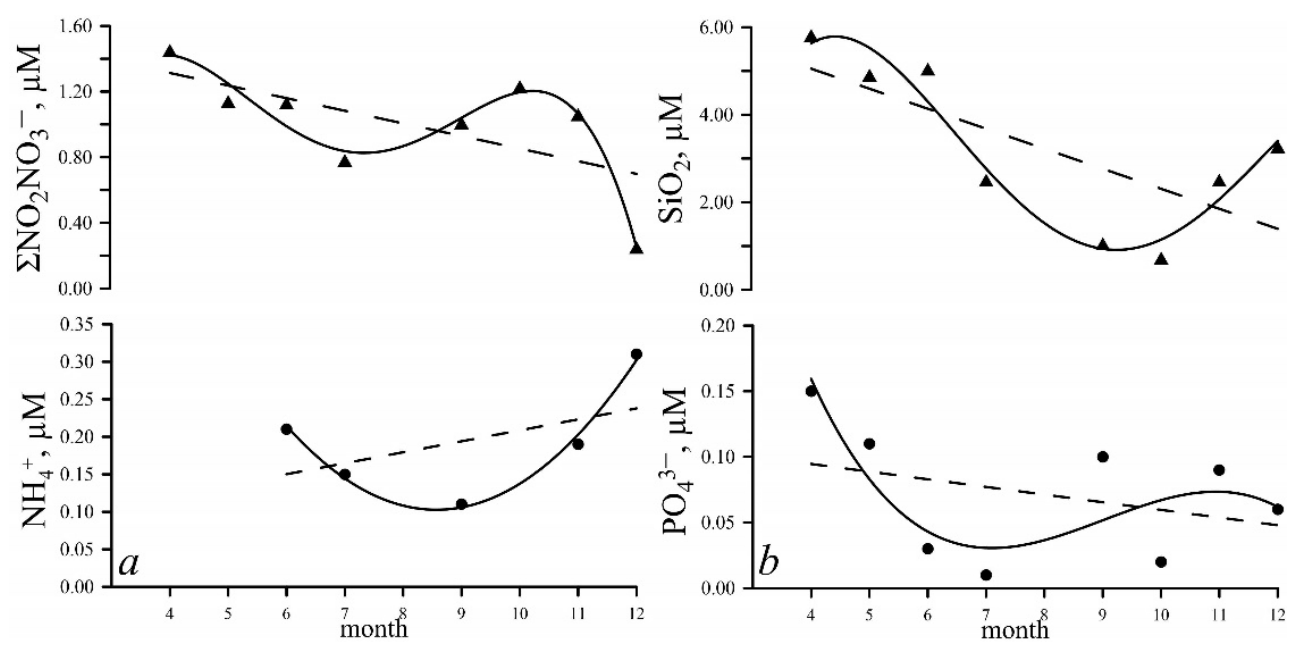

F i g. 6. Intra-annual dynamics of the nutrients concentration 
By December, the content of nitrogen oxidized forms decreases to $0.25 \mu \mathrm{M}$, however, a peak of their concentration $(1.23 \mu \mathrm{M})$ was noted in October, which is determined by the contribution of wind impact, leading to the destruction of the UML and the influx of nutrients from the underlying layers [26]. In the dynamics of ammonium, a different character is manifested: a decrease in concentration from June to September (from 0.21 to $0.11 \mu \mathrm{M}$ ) and its increase to $0.19 \mu \mathrm{M}$ in November and to $0.31 \mu \mathrm{M}$ in December (Fig. 6). The share of nitrogen reduced forms increased from 10\% in September to $22-38 \%$ in November and to $55 \%$ in December. Based on the change in the concentration and ratio of oxidized and reduced forms of nitrogen, it can be assumed that, in addition to the spring bloom, in early November, the autumn phytoplankton bloom and the development of its biomass begins, and in December - attenuation, as evidenced by a decrease in the concentration of oxidized forms of nitrogen, which are involved in the oxidation of accumulated organic matter, and an increase in the content of ammonium as an intermediate product.

In November, the concentration of phosphates also slightly increases to $0.09 \mu \mathrm{M}$ and by December it is reduced by half; in November - December an increase in the of silicic acid was noted up to $3.3 \mu \mathrm{M}$.

In addition to seasonal dynamics, attention is drawn to the interannual variability of the concentration of the considered nutrients (Fig. 2, Table). So, in 2017, in different seasons their maximum concentrations, which were two times higher than in 2016, 2018, and 2019 were observed. In the summer of 2019, on the contrary, the minimum concentrations of nutrients, compared to previous years, were noted. This can be explained by the impact of meteorological conditions and the hydrodynamic factor, as well as by the hypothesis of pulsating bloom described in [16]. So, the winters of 2015 and 2016 preceding 2017 were relatively soft (http://pogoda-service.ru/archive_gsod_res.php), which contributed to a weakening of the convective vertical exchange, a lower supply of nutrients to the upper water layer and their accumulation in the underlying layers. In 2017, the intensification of vertical exchange led to a significant supply of nutrients to the upper water layer, which contributed to an increase in their content. The combination of a number of factors - the content of nutrients, meteorological conditions and illumination, which are the main characteristics, led to an outbreak of blooming in the summer of 2017 (Fig. 7).

Based on the change in the concentration of nutrients, as well as taking into account the absence of their convective transport with deep waters and a decrease in the contribution of waters carried by the Rim Current and coastal currents, it can be assumed that in the summer period the involvement of nutrients in biological and biogeochemical processes makes a predominant contribution to their dynamics. 


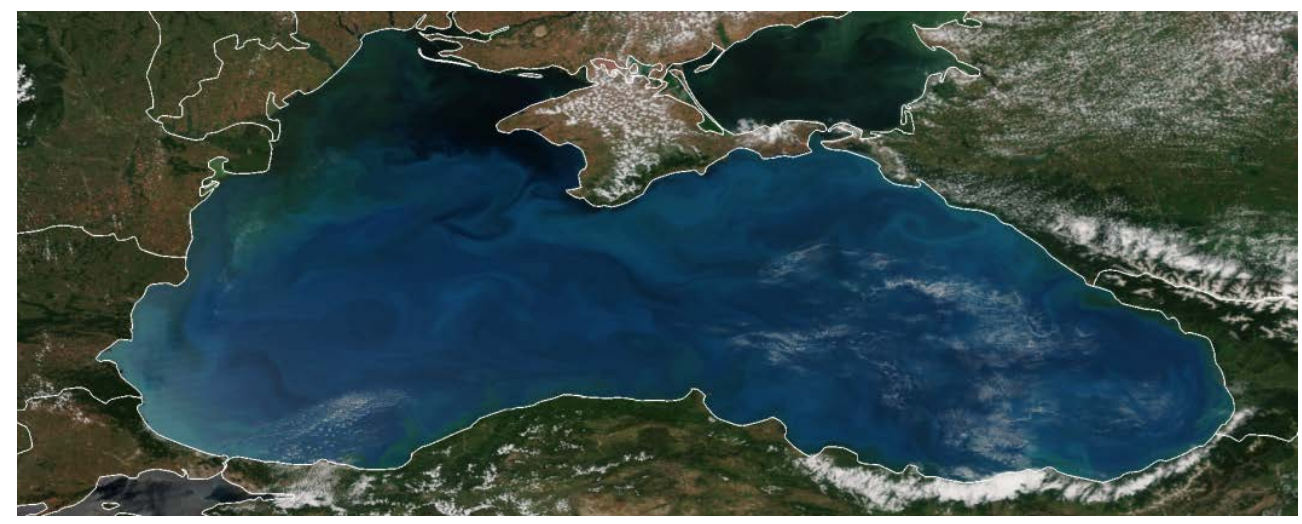

F i g. 7. Satellite image of the Black Sea surface, 26.06.2017 (https://satellitemaps.nesdis.noaa.gov/arcgis/apps/webappviewer/index.html?id=5decde660f5f47189d 0433cd2a1500ac) (turquoise color points at the coccolithophore bloom)

We can also note a decrease in the concentration of the listed nutrients in 2016-2019 compared to 2009-2014 [11] (Fig. 8). According to the average variation of nutrient concentration, a decrease of its concentration, compared to 2014, was revealed: the amount of nitrates - nitrites is almost 2 times, ammonium -9 times, phosphates -6 times, silicates -4 times [11]. A decrease in the proportion of the contribution of ammonium to the total inorganic nitrogen (from 90 to 23\%) may indicate a decrease in the organic matter flow. Thus, since 2009, a tendency towards a decrease in the nutrient content in the surface layer of the Black Sea, which indicates a decrease in the level of eutrophication and an improvement of the water quality, took place.

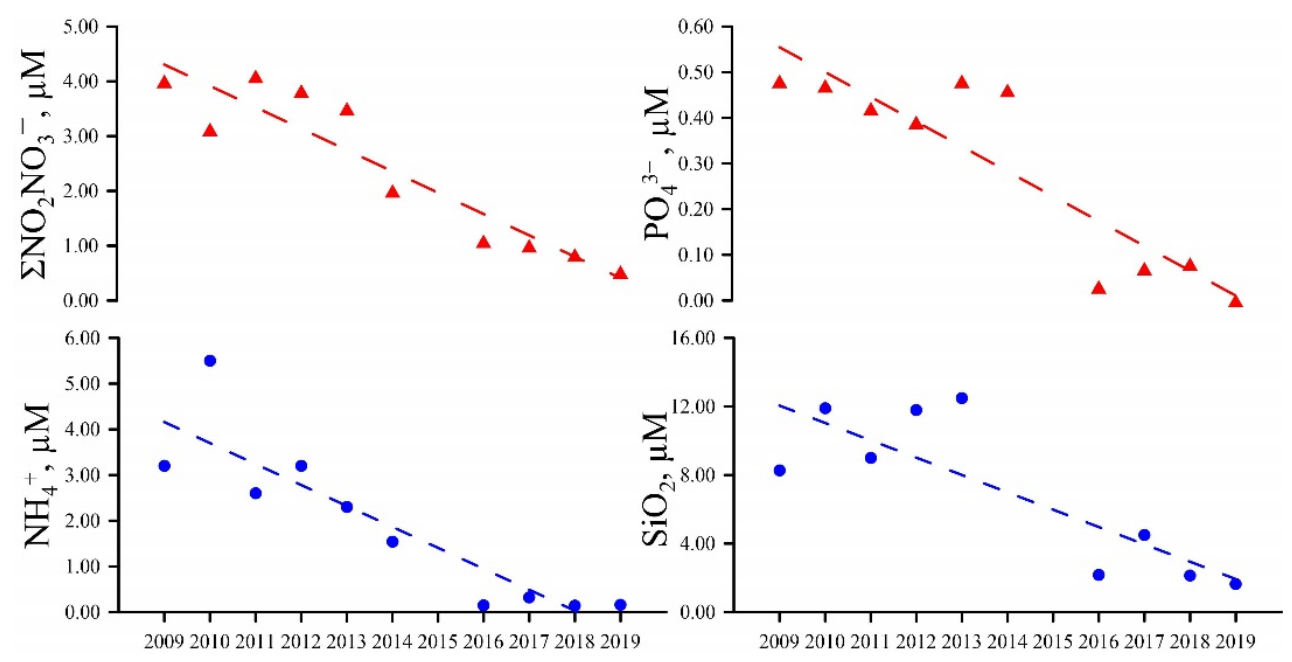

F i g. 8. Interannual nutrients dynamic (the data for 2009-2014 are taken from [11]; the data for 2019 are given based on one survey) 
The spatial distribution of nutrients was heterogeneous (Fig. 3-5). In spring and autumn, the spatial dynamics of the concentration of inorganic forms of nitrogen was mainly determined by the hydrodynamic effect [20, 25]: in the northwestern part, the influx with the river runoff occurs, with the transport from the Rim Current, with local gyres (as indicated by the zones of local maxima); in the deep-water part - due to the rise of deep waters enriched with nutrients. In the eastern part of Crimea, the main source of nitrogen inorganic forms is the Sea of Azov, in the Caucasian polygon - river runoff in the coastal areas. In summer, the distribution of nutrients (sum of nitrates - nitrites) is mainly determined by biological and chemical processes. In addition, in the late spring and summer periods the maximum concentrations of inorganic forms of nitrogen were recorded in coastal areas (Fig. 3, 5) - local maximum concentration in the areas with significant anthropogenic impact [21, 22]. This is most clearly manifested in the eastern part of the Crimean coast.

The distribution of phosphates was mostly uniform. The maximum concentrations of phosphorus and silicon in summer were also noted in the coastal regions and in the Kerch Strait region.

At the same time, it should be noted that during the entire study period in the coastal areas no rise of cold deep waters, which serve as an additional source of nutrients, was observed. Consequently, an increase in the concentration of nutrients during this period is most likely the result of anthropogenic activities (municipal wastewater, an increase in the recreational load, etc.).

\section{Conclusions}

The concentration of nutrients was determined by a combination of physical and biological-chemical processes, and it is rather difficult to separate the contribution of each one individually. The regime of nutrients in the Black Sea upper layer is subject to regular intra-annual variability: in winter, they accumulate due to their removal from the underlying water layers and due to their minimal consumption. During the transition from winter to spring, as the accumulation of nutrients and their additional input with the river runoff, conditions for photosynthesis are created. Then their dynamics is determined by their involvement in biological and chemical processes. By the end of the spring and the beginning of the summer period, the concentration of nutrients decreases due to their extraction by phytoplankton during photosynthesis, as well as due to the weakening of the vertical convection intensity, and by the middle of the summer period their minimum content is observed. Some delay in the variation of the silicic acid concentration was noted: first of all, phytoplankton extract nitrogen and phosphorus compounds, while the accumulation of silicic acid occurs. In autumn, the concentration of nutrients is determined by their vertical transport with deep waters. By the middle of the autumn period, a sufficient amount of nutrients is accumulated, which creates the preconditions for the second peak of 672 
phytoplankton bloom. By December, a decrease in the concentration of nutrients is observed.

Based on the spatial distribution of nutrients, it was assumed that in the central deep-water part of the sea their concentrations were mainly determined by the physical processes of water transport. The increased concentrations of nutrients in coastal areas, in addition to physical transfer, are probably also associated with the anthropogenic factor impact - with their entry from coastal sources or with their formation as a result of biogeochemical processes with the participation of organic matter.

In the interannual dynamics of nutrients in 2016-2019, the trends of a decrease in the concentration of the sum of nitrates - nitrites, an increase in the concentration of phosphorus and the absence of visible changes in the concentration of silicic acid and ammonium are noted. At the same time, the concentrations of all of the listed nutrients were significantly lower than in 2009-2014. A decrease in the proportion of the contribution of ammonium to the total inorganic nitrogen (from 90 to 23\%) may indicate a decrease in the organic matter flow as a whole. Thus, a decrease in the level of eutrophication and an improvement in the quality of the Black Sea waters can be noted.

\section{REFERENCES}

1. Ivanov, V.A. and Belokopytov, V.N., 2013. Oceanography of the Black Sea. Sevastopol: Marine Hydrophysical Institute, $210 \mathrm{p}$.

2. Dineva, S., 2013. Black Sea Water Environment along the Bulgarian Coast. Bulgarian Journal of Agricultural Science, 19(Suppl. 1), pp. 6-11. Available at: https://agrojournal.org/19/01s-02.html [Accessed: 21 November 2021].

3. Palazov, A., Ciliberti, S., Peneva, E., Gregoire, M., Staneva, J., Lemieux-Dudon, B., Masina, S., Pinardi, N., Vandenbulcke, L. [et al.], 2019. Black Sea Observing System. Frontiers in Marine Science, 6, 315. doi:10.3389/fmars.2019.00315

4. Belokopytov, V.N., Fomin, V.V. and Ingerov, A.V., 2017. On Multidisciplinary Investigations of Dangerous Natural Phenomena in the Azov-Black Sea Basin. Physical Oceanography, (3), pp. 28-44. doi:10.22449/1573-160X-2017-3-28-44

5. Yunev, O., Carstensen, J., Moncheva, S., Khaliulin, A., Ærtebjerg, G. and Nixon, S., 2007. Nutrient and Phytoplankton Trends on the Western Black Sea shelf in Response to Cultural Eutrophication and Climate Changes. Estuarine, Coastal and Shelf Science, 74(1), pp. 63-76. doi:10.1016/j.ecss.2007.03.030

6. Capet, A., Stanev, E.V., Beckers, J.-M., Murray, J.W. and Grégoire, M., 2016. Decline of the Black Sea Oxygen Inventory. Biogeosciences, 13(4), pp. 1287-1297. doi:10.5194/bg-131287-2016

7. Pakhomova, S., Vinogradova, E., Yakushev, E., Zatsepin, A., Shtereva, G., Chasovnikov, V. and Podymov, O., 2014. Interannual Variability of the Black Sea Proper Oxygen and 
Nutrients Regime: The Role of Climatic and Anthropogenic Forcing. Estuarine, Coastal and Shelf Science, 140, pp. 134-145. https://doi.org/10.1016/j.ecss.2013.10.006

8. Stewart, K., Kassakian, S., Krynytzky, M., DiJulio, D. and Murray, J.W., 2007. Oxic, Suboxic, and Anoxic Conditions in the Black Sea. In: V. Yanko-Hombach, A.S. Gilbert, N. Panin, P. M. Dolukhanov, eds., 2007. The Black Sea Flood Question: Changes in Coastline, Climate, and Human Settlement. Dordrecht: Springer, pp. 1-21. doi:10.1007/978-1-4020-53023_1

9. Konovalov, S., Murray, J.W., Luther, G.W. and Tebo, B.M., 2006. Processes Controlling the Redox Budget for the Oxic/Anoxic Water Column of the Black Sea. Deep-Sea Research Part II: Topical Studies in Oceanography, 53(17-19), pp. 1817-1841. doi:10.1016/j.dsr2.2006.03.013

10. Konovalov, S.K. and Murray, J.W., 2001. Variations in the Chemistry of the Black Sea on a Time Scale of Decades (1960-1995). Journal of Marine Systems, 31(1-3), pp. 217-243. doi:10.1016/S0924-7963(01)00054-9

11. BSC, 2019. State of the Environment of the Black Sea (2009-2014/5). Publications of the Commission on the Protection of the Black Sea Against Pollution (BSC) 2019. Istanbul, Turkey, 811 p. [online] Available at: http://blacksea-commission.org/SoE20092014/SoE2009-2014.pdf [Accessed: 13 February 2021].

12. Alcamo, J., Moreno, J.M., Nováky, B., Bindi, M., Corobov, R., Devoy, R.J.N., Giannakopoulos, C., Martin, E., Olesen, J.E. and Shvidenko, A., 2007. Europe. In: IPCC, 2007. Climate Change 2007: Impacts, Adaptation and Vulnerability. Contribution of Working Group II to the Fourth Assessment Report of the Intergovernmental Panel on Climate Change. Cambridge, UK: Cambridge University Press. Chapter 12, pp. 541-580. Available at: https://www.researchgate.net/publication/271906999_Chapter_12-_Europe [Accessed: 01 March 2021].

13. Dineva, S., 2010. Climate Change: Outcomes Related to the Black Sea. In: C. Avanzini, ed., 2010. MWWD 2010 - 6th International Conference on Marine Waste Water Discharges and Coastal Environment, Langkawi, Malaysia, 25-29 October, 2010. MWWD Organization.

14. Oguz, T., Cokacar, T., Malanotte-Rizzoli, P., and Ducklow, H., 2003. Climatic Warming and Accompanying Changes in the Ecological Regime of the Black Sea during 1990s. Global Biogeochemical Cycles, 17(3), 1088. doi:10.1029/2003GB002031

15. Rosenberg, A.A., Kirkwood, G.P., Crombie, J.A. and Beddington, J.R., 1990. The Assessment of Stocks of Annual Squid Species. Fisheries Research, 8(4), pp. 335-350. https://doi.org/10.1016/0165-7836(90)90003-E

16. Mikaelyan, A.S., Pautova, L.A., Chasovnikov, V.K., Mosharov, S.A. and Silkin, V.A., 2015. Alternation of Diatoms and Coccolithophores in the North-eastern Black Sea: a Response to Nutrient Changes. Hydrobiologia, 755(1), pp. 89-105. doi:10.1007/s10750-015-2219-z

17. Zaitsev, Yu. and Mamaev, V., 1997. Marine Biological Diversity in the Black Sea: a Study of Change and Decline. Programme for the Environmental Management and Protection of the Black Sea. New York: United Nations Publications, 217 p. 
18. Bordovskiy, O.K and Chernyakova, A.M., eds., 1992. Modern Methods of Ocean Hydrochemical Investigations. Moscow: P.P.Shirshov Institute of Oceanology, 201 p. (in Russian).

19. Solórzano, L., 1969. Determination of Ammonia in Natural Waters by Phenolhypochlorite Method. Limnology and Oceanography, 14(5), pp. 799-801. https://doi.org/10.4319/lo.1969.14.5.0799

20. Artamonov, Yu.V., Skripaleva, E.A., Fedirko, A.V., Shutov, S.A., Derjushkin, D.V., Shapovalov, R.O., Shapovalov, Yu.I. and Shcherbachenko, S.V., 2020. Waters Circulation in the Northern Part of the Black Sea in Summer - Winter of 2018. Ecological Safety of Coastal and Shelf Zones of Sea, (1), pp. 69-90. doi:10.22449/2413-5577-2020-1-69-90 (in Russian).

21. Petrenko, O.A., Zhugaylo, S.S. and Avdeeva, T.M., 2015. Results of Long-term Investigations on the Contamination Level in the Azov and Black Seas Fishery Basin Marine Environment. YugNIRO Proceedings, 53, pp. 4-18 (in Russian).

22. Ivanov, V.A., Sovga, E.E., Khmara, T.V. and Zima, V.V., 2018. Thermochaline Regime of the Karkinite Bay and Environmental Consequences of Nature Management. Ecological Safety of Coastal and Shelf Zones of Sea, (3), pp. 22-33. doi:10.22449/2413-5577-2018-3-2233 (in Russian).

23. Melnikova, T.N., 2013. [Monitoring of the Chemical Composition of the Waters of the Kuban River Basin]. International Journal of Applied and Fundamental Research, (11), pp. 52-53. Available at: https://applied-research.ru/ru/article/view?id=4312 [Accessed: 21 November 2021] (in Russian).

24. Kudymova, A.V. and Mamas', N.N., 2017. [The Ecological Situation of the Afips River in the Village of Afipsky, Seversky District]. In: A. G. Koshchaev, ed., 2017. [Proceedings of $X$ Russian Conference of Young Scientists dedicated to the 120th anniversary of I.S. Kosenko, "Scientific support for the agro-industrial complex". Krasnodar, Russia, 26-30 November 2016]. Krasnodar: Kuban State Agrarian University named after I.T. Trubilin, pp. 1808-1809. (in Russian).

25. Artamonov, Yu.V., Fedirko, A.V., Skripaleva, E.A., Shutov, S.A., Deryushkin, D.V., Kolmak, R.V., Zavyalov, D.D., Shapovalov, R.O., Shapovalov, Yu.I. and Shcherbachenko, S.V., 2019. Water Structure in the Area of the Rim Black Sea Current in Spring and Summer 2017 (94th, 95th cruises of the R/V "Professor Vodyanitsky"). Ecological Safety of Coastal and Shelf Zones of Sea, (1), pp. 16-28. doi:10.22449/2413-5577-2019-1-16-28 (in Russian).

26. Mikaelyan, A.S., Shapiro, G.I., Chasovnikov, V.K., Wobus, F. and Zanacchi, M., 2017. Drivers of the Autumn Phytoplankton Development in the Open Black Sea. Journal of Marine Systems, 174, pp. 1-11. https://doi.org/10.1016/j.jmarsys.2017.05.006

27. Cokacar, T., Oguz, T. and Kubilay, N., 2004. Satellite-Detected Early Summer Coccolithophore Blooms and Their Interannual Variability in the Black Sea. Deep-Sea Research Part I: Oceanographic Research Papers, 51(8), pp. 1017-1031. doi:10.1016/j.dsr.2004.03.007

28. Silkin, V.A., Abakumov, A.I., Pautova, L.A., Pakhomova, S.V. and Lifanchuk, A.V., 2016. Mechanisms of Regulation of Invasive Processes in Phytoplankton on the Example of the 
North-Eastern Part of the Black Sea. Aquatic Ecology, 50(2), pp. 221-234. https://doi.org/10.1007/s10452-016-9570-7

About the author:

Natalia A. Orekhova, Leading Research Associate, Head of Marine Biogeochemistry Department, Marine Hydrophysical Institute of RAS (2 Kapitanskaya str., Sevastopol, 299011, Russian Federation), Ph.D. (Geogr.), ORCID ID: 0000-0002-1387-970X, ResearcherID: I-17552017, Scopus Author ID: 35784884700, natalia.orekhova@mhi-ras.ru

The author has read and approved the final manuscript.

The author declares that he has no conflict of interest. 